\title{
EFFECTS OF TEMPERATURE ON THE SPECTRAL EMISSIVITY OF C/SiC COMPOSITES
}

\author{
"YUFENG ZHANG*, JINGMIN DAI**, XIAODONG LU*, YUANQING WU* \\ *College of New Energy, Bohai University, \\ Jinzhou 121013, China \\ **School of Electrical Engineering and Automation, Harbin Institute of Technology, \\ Harbin 150001, China \\ "E-mail: zyf81@aliyun.com
}

Submitted September 15, 2015; accepted February 15, 2016

\begin{abstract}
Keywords: Spectral emissivity, Temperature characteristics, C/SiC composites
The effect of temperature on the infrared spectral emissivity of C/SiC composites as a thermal protection material has been studied, using a measurement system based on a FT-IR spectrometer. The spectral emissivity of C/SiC composites in the wavelength range 3-20 $\mu \mathrm{m}$ and in the temperature range from $1000 \mathrm{~K}$ to over $2000 \mathrm{~K}$ was measured. Based on the analysis of the measured spectral emissivity, variations of the spectral emissivity with temperature were studied. The relationship between emissivity and temperature in some certain wavelength was found.
\end{abstract}

\section{INTRODUCTION}

With the continuous increase of flight speed, thermal protection materials for spacecraft vehicles have to meet higher requirements [1]. In high-speed flight, the thermal protection system of the spacecraft is important to provide protection of the equipment inside the vehicle by reducing the surface temperature. Thermal radiation is one of the main ways of heat dissipation. The material of the thermal protection system therefore plays a key role to dissipate the heat [2].

$\mathrm{C} / \mathrm{SiC}$ composite is one of the typical ceramic materials used in thermal protection systems, because it has the characteristics of high melting point and high emissivity [3, 4]. When the surface temperature rises rapidly, a large amount of thermal energy will escape into space in the form of radiation. An effective way to enhance the efficiency of the radiation is improving the emissivity of $\mathrm{C} / \mathrm{SiC}$ composites [5].

In order to characterize the thermal radiation performance, the emissivity is the essential parameter to determine the cooling efficiency of thermal radiation [6-8]. Evaluation of the emissivity of thermal protection materials is therefore an important problem in spacecraft design. Measurement equipment for the emissivity of $\mathrm{C} / \mathrm{SiC}$ composites is based on Fourier-transform infrared (FT-IR) spectrometers that can measure the radiation in the spectral range from near to far infrared [9, 10]. Analyzing the change of the spectral emissivity of
$\mathrm{C} / \mathrm{SiC}$ composites as a function of the temperature is the basis for estimating thermal radiation performance and the ability of thermal protection.

\section{EXPERIMENTAL}

Measurement principle

Spectral emissivity, defined as the ratio of the radiation power of the object $(L(\lambda, T))$ to the blackbody radiation power $\left(L_{b b}(\lambda, T)\right)$ at the same temperature [11], can be expressed as

$$
\varepsilon(\lambda, T)=\frac{L(\lambda, T)}{L_{b b}(\lambda, T)} .
$$

In Figure 1, using the external radiation measurement mode of the FT-IR spectrometer, the radiance of the specimen and blackbody, respectively, is measured at the same temperature. The output signal of the FT-IR spectrometer is proportional to the strength of radiation in the two cases, respectively, and is given by

$$
\begin{gathered}
S_{s}(\lambda, T)=R(\lambda) \cdot f(d, r) \cdot\left[L_{s}(\lambda, T)+L_{n}\left(T_{e}\right)\right] \\
S_{b b}(\lambda, T)=R(\lambda) \cdot f(d, r) \cdot\left[L_{b b}(\lambda, T)+L_{n}\left(T_{e}\right)\right],
\end{gathered}
$$

where $S_{s}(\lambda, T)$ and $S_{b b}(\lambda, T)$ is the output signal of the FT-IR spectrometer, $R(\lambda)$ is the spectral responsivity, $f(d, r)$ is a constant related to the dimension $d$ and the infrared reflectivity $r$ of the optical elements, $L_{s}(\lambda, T)$ and 
$L_{b b}(\lambda, T)$ are the radiation of specimen and blackbody, respectively, and $L_{n}\left(T_{e}\right)$ is the environmental radiation.

Combining Equations 1 and 2, one obtains

$$
\begin{aligned}
\varepsilon(\lambda, T)= & \frac{L(\lambda, T)}{L_{b b}(\lambda, T)} \\
= & \frac{\frac{S_{s}(\lambda, T)}{R(\lambda) \cdot f(d, r)}-L_{n}\left(T_{e}\right)}{\frac{S_{b b}(\lambda, T)}{R(\lambda) \cdot f(d, r)}-L_{n}\left(T_{e}\right)} . \\
= & \frac{S_{s}(\lambda, T)-R(\lambda) \cdot f(d, r) \cdot L_{n}\left(T_{e}\right)}{S_{b b}(\lambda, T)-R(\lambda) \cdot f(d, r) \cdot L_{n}\left(T_{e}\right)}
\end{aligned}
$$

When the output signal of the FT-IR spectrometer caused by the environment temperature $T_{e}$ is equal to $S_{n}$, which can be expressed as

$$
S_{n}=R(\lambda) \cdot f(d, r) \cdot L_{n}\left(T_{e}\right),
$$

the emissivity of the specimen is given by

$$
\varepsilon(\lambda, T)=\frac{S_{s}(\lambda, T)-S_{n}}{S_{b b}(\lambda ; T)-S_{n}}
$$

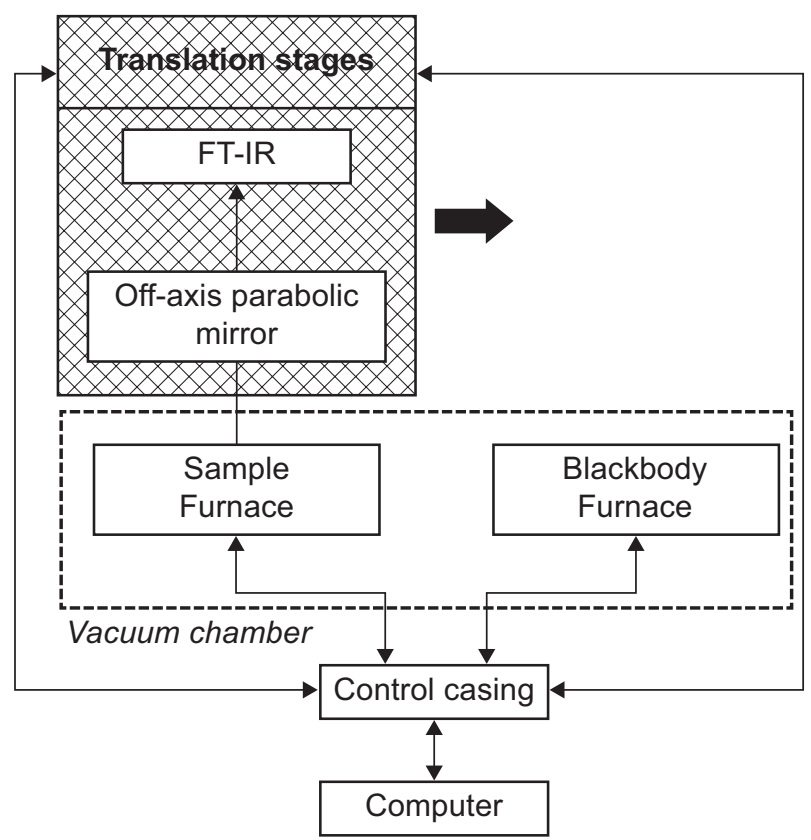

Figure 1. Block diagram of measurement principle.

\section{Measurement system}

A spectral emissivity measurement system based on the principle of the energy comparing method was used to carry out the experiment. The measurement system that uses a FT-IR spectrometer to measure the spectral emissivity of $\mathrm{C} / \mathrm{SiC}$ composite specimen in the wavelength range $3-20 \mu \mathrm{m}$ and in the temperature range from $1000 \mathrm{~K}$ to over $2000 \mathrm{~K}$ had been built at Bohai University (BHU, Jinzhou, China). Figure 2, shows a photograph of the measurement system, which includes a vacuum chamber containing the blackbody furnace and the specimen furnace, a FT-IR spectrometer, a group of off-axis parabolic mirrors plated with gold, and a control panel.

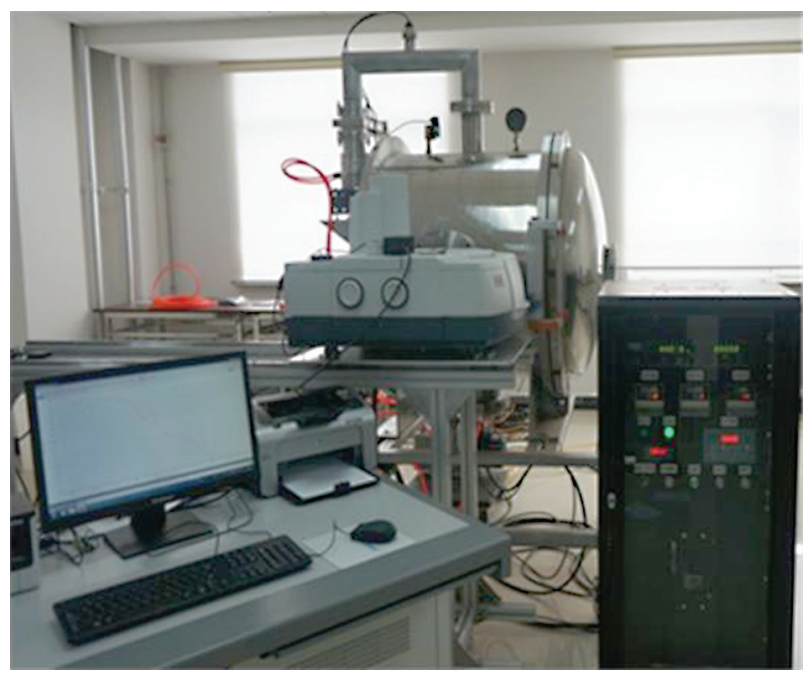

Figure 2. Photograph of the measurement system.

In the measurement system, the heating device for specimen and blackbody was placed into high vacuum to prevent the oxidation of the heating element device. The design for the propagation path of radiation is shown in Figure 3. Radiation emitted from specimen or blackbody was reflected two times. The focal position of two off-axis parabolic mirror was overlapped. The radiation detected by the FT-IR spectrometer was parallel and consistent with the normal direction of the specimen and blackbody.

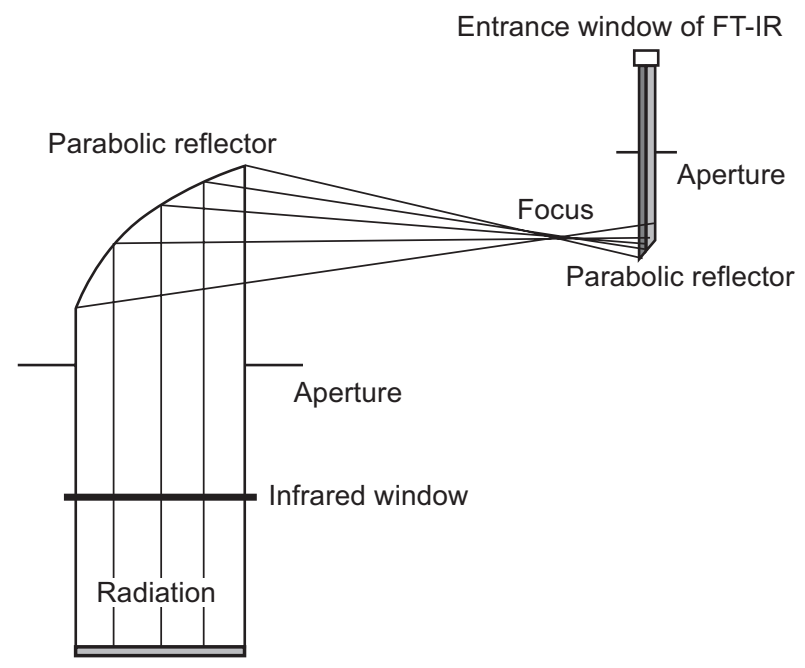

Figure 3. Optical path of measurement system.

Sample preparation

The specimen of $\mathrm{C} / \mathrm{SiC}$ composites was prepared by an isothermal-decompression chemical vapour infiltration (CVI) process with three-dimensional long 
carbon fiber (T300, 3000) woven preform. The preform was fabricated by a three-dimensionalfour-step method with 40 vol. $\%$ of carbon fiber. Firstly, a $0.2 \mathrm{~mm}$ thick carbon layer was uniformly deposited on the long carbon fiber surface by pyrolysis of propylene at $960^{\circ} \mathrm{C}$. Secondly, SiC layers were formed on the pore surfaces of activated carbons by permeating and depositing $\mathrm{SiC}$ from a pyrolysis reaction between hydrogen $\left(\mathrm{H}_{2}\right)$ and trichloromethylsilane $\left(\mathrm{CH}_{3} \mathrm{SiCl}_{3}, \mathrm{MTS}\right)$ at $1000^{\circ} \mathrm{C}$. Du-ring this process, hydrogen was used as carrier gas, which brought the reaction gas into the high temperature furnace with a vacuum of $0.01 \mathrm{MPa}$. The flow rate ratio of hydrogen and MTS is 10:1 and the deposition pressure is $5 \mathrm{kPa}$. The density of the $\mathrm{C} / \mathrm{SiC}$ composite specimen is about $2 \mathrm{~g} \cdot \mathrm{cm}^{-3}$, and the residual porosity is approximately $15-17 \%$.

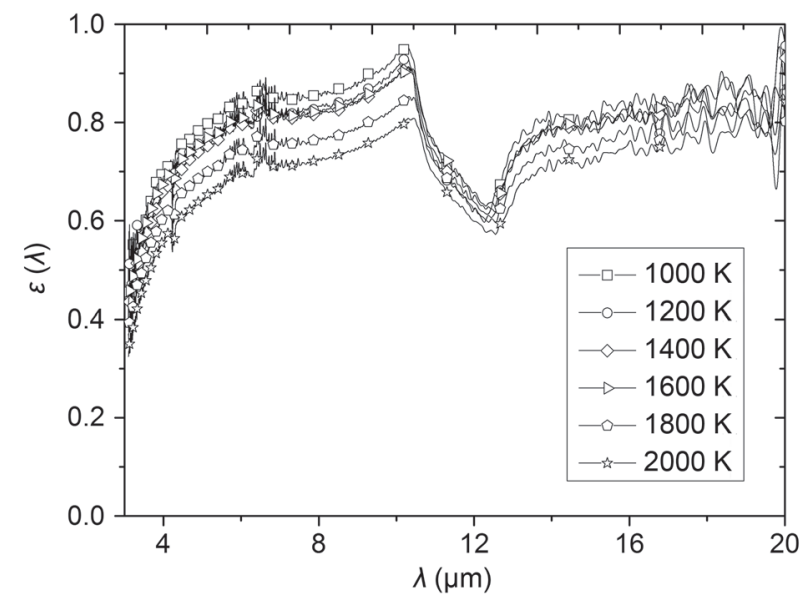

Figure 4. Spectral emissivity of $\mathrm{C} / \mathrm{SiC}$ composite specimen.

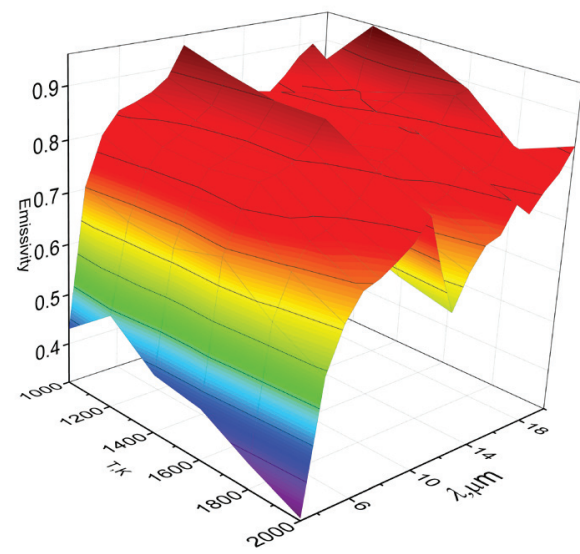

Figure 5. Temperature and wavelength dependence of emissivity.

\section{RESULTS AND DISCUSSION}

According to the typical working temperature of $\mathrm{C} / \mathrm{SiC}$ composite used for the thermal protection of spacecraft, the spectral emissivity of $\mathrm{C} / \mathrm{SiC}$ composite specimen was measured in the temperature range from $1000 \mathrm{~K}$ to $2000 \mathrm{~K}$. The measurement results are shown in Figure 4.

Figure 5 shows that the emissivity at most wavelengths in the range from $3 \mu \mathrm{m}$ to $20 \mu \mathrm{m}$ decreases with increasing temperature. This downward variation of the emissivity with temperatures is typical and expected for non-metal materials.

As shown in Figure 6, the emissivity at wavelengths of $18 \mu \mathrm{m}$ and $20 \mu \mathrm{m}$ increased when the temperature of specimen exceeds $1600 \mathrm{~K}$ and $1800 \mathrm{~K}$, respectively. The emissivity at the wavelength of $12 \mu \mathrm{m}$ approximately remains 0.62 and does not exhibit a significant variation with temperature.

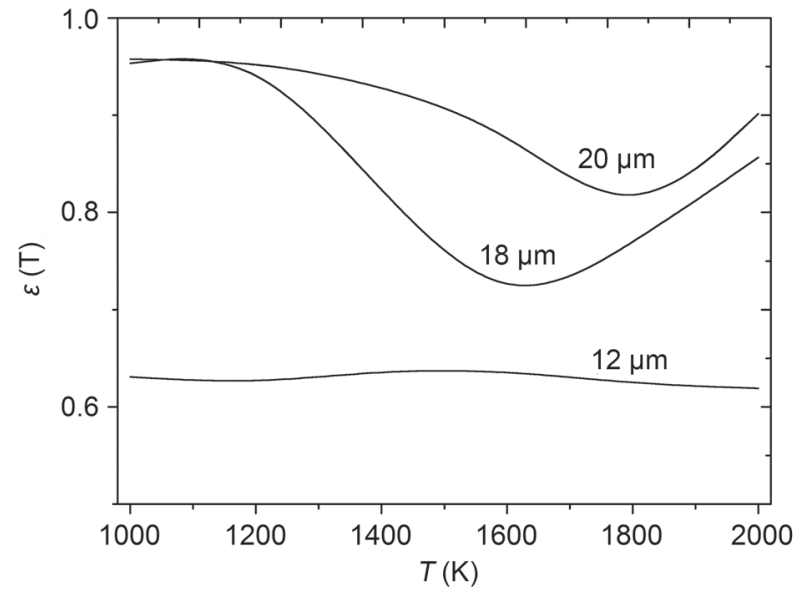

Figure 6 . Temperature dependence of emissivity at $3 \mu \mathrm{m}, 18 \mu \mathrm{m}$ and $20 \mu \mathrm{m}$.

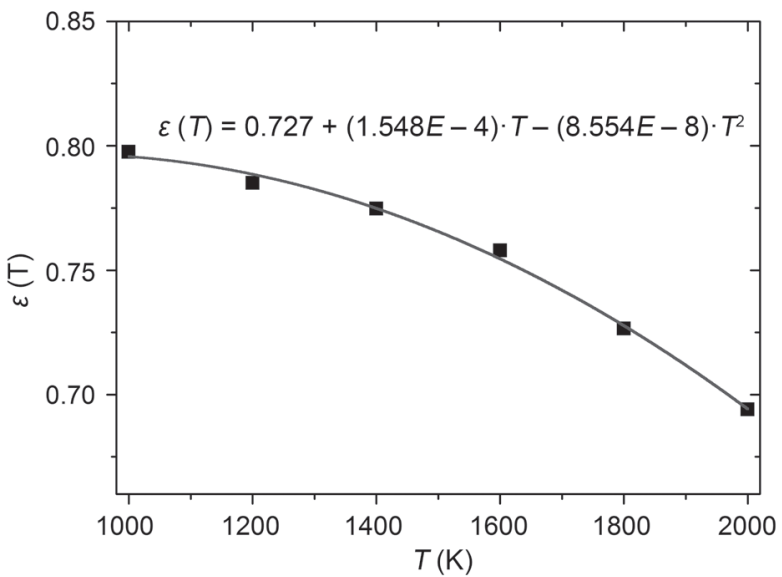

Figure 7. Temperature dependence of the spectral bandwidth emissivity. 
For the further discussion of the radiation performance of $\mathrm{C} / \mathrm{SiC}$ composites, the spectral bandwidth emissivity of specimen was calculated by the formula [12]

$$
\varepsilon_{3-20}=\frac{\int_{20}^{3} L_{s}(\lambda, T) d \lambda}{\int_{20}^{3} L_{b b}(\lambda, T) d \lambda} .
$$

The thus calculated spectral bandwidth emissivity from $3 \mu \mathrm{m}$ and $20 \mu \mathrm{m}$ is shown in Figure 7. The spectral bandwidth emissivity decreased with the increase of the specimen temperature. When the temperature of the specimen reached $2000 \mathrm{~K}$, the bandwidth emissivity decreases to about 0.7 , which is $85 \%$ of the emissivity value at $1000 \mathrm{~K}$. Based on polynomial fitting, the following polynomial expression is obtained for the temperature dependence of the emissivity:

$$
\varepsilon(T)=0.727+\left(1.548 \times 10^{-4}\right) T-\left(8.554 \times 10^{-8}\right) T^{2}
$$

\section{CONCLUSIONS}

Spectral emissivity data of a $\mathrm{C} / \mathrm{SiC}$ composite were measured by a measurement system based on a FT-IR spectrometer. Changes of the spectral emissivity of the $\mathrm{C} / \mathrm{SiC}$ composite specimen with temperature and wavelength were discussed. With increasing temperature from $1000 \mathrm{~K}$ to $2000 \mathrm{~K}$, the spectral bandwidth emissivity of $\mathrm{C} / \mathrm{SiC}$ composite specimen decreased from 0.8 to 0.7 . A polynomial fit relation was proposed for the temperature dependence of the spectral bandwidth emissivity.

\section{Acknowledgements}

This paper is based upon work supported by the National Science Foundation of China (grant no. 61575029).

\section{REFERENCES}

1. Xie G. N., Wang Q., Sunden B., Zhang W. (2013): Thermomechanical optimization of lightweight thermal protection system under aerodynamic heating. Applied Thermal Engineering, 59(1), 425-434. doi:10.1016/j. applthermaleng.2013.06.002
2. Tobe R. J., Grandhi R. V. (2013): Hypersonic vehicle thermal protection system model optimization and validation with vibration tests. Aerospace Science and Technology, 28(1), 208-213. doi:10.1016/j.ast.2012.11.001

3. Wu H., Xie C., Zhang W., Zhang J. (2013): Fabrication and properties of $2 \mathrm{D} \mathrm{C} / \mathrm{C}-\mathrm{ZrB} 2-\mathrm{ZrC}-\mathrm{SiC}$ composites by hybrid precursor infiltration and pyrolysis. Advances in Applied Ceramics, 112(6), 366-373. doi:10.1179/1743676 113Y.0000000092

4. Ortona A., Badini B., Liedtke V., Wilhelmi C. (2013): Hetoroporous heterogeneous ceramics for reusable thermal protection systems. Journal of Materials Research, 28(17), 2273-2280. doi: 10.1557/jmr.2013.70

5. Alfano D., Scatteia L., Cantoni S., Balat-Pichelin M. (2009): Emissivity and catalycity measurements on SiCcoated carbon fibre reinforced silicon carbide composite. Journal of the European Ceramic Society, 29(10), 20452051. doi:10.1016/j.jeurceramsoc.2008.12.011

6. Wang H., Chen D., Wang G., Long Y., Luo J., Liu L. (2013): Measurement technology for material emissivity under high temperature dynamic heating conditions. Measurement, 46(10), 4023-4031. doi:10.1016/j.measurement.2013.07.041

7. Teodorescua G., Jonesb P., Overfelta R. (2008). Normal emissivity of high-purity nickel at temperatures between 1440 and 1605K. Journal of Physics and Chemistry of Solids, 69(1), 133-138. doi:10.1016/j.jpcs.2007.08.047

8. Cao G., Weber S.J., Martin S.O., Sridharan K., Anderson M.H.,Allen T. R. (2010): Spectral Emissivity Measurements of Candidate Alloys for Very High Temperature Reactors in High Temperature Air Environment. Transactions of the American Nuclear Society, 102, 827-828.

9. Righini F., Robert R., Rosso A. (1985): Measurement of thermophysical properties by a pulse-heating method: Niobium in the range 1000-2500 K. International journal of thermophysics, 6(6), 681-693. doi:10.1007/BF00500339

10. Wang Z.W., Wang Y. M., Liu Y., Xu J. L., Guo L. X., Zhou $Y(2011)$ : Microstructure and infrared emissivity property of coating containing TiO 2 formed on titanium alloy by microarc oxidation. Current Applied Physics, 11(6), 14051409. doi:10.1016/j.cap.2011.04.011

11. Hanssen L. M., Mekhontsev S. N., Khromchenko V. B. (2010): Validation of the infrared emittance characterization of materials through intercomparison of direct and indirect methods. International Journal of Thermophysics, 31(10), 1972-1978. doi:10.1007/s10765-008-0507-9

12. Rebouta L., Pitaes A., Andritschky M., Capela P., Cerqueira M. F., Matilainen A. (2015): Solar selective absorbers based on $\mathrm{Al}_{2} \mathrm{O}_{3}$ : W cermets and AlSiN/AlSiON layers. Solar Energy Materials and Solar Cells, 137, 93100. doi:10.1016/j.solmat.2015.01.029 